\title{
Spontaneous Rupture of an Ovarian Dermoid Cyst Associated with Intra-Abdominal Chemical Peritonitis: Characteristic CT Findings
}

\author{
Koirala S, Adhikari K, Khadka S
}

\author{
Department of Radio Diagnosis and Imaging, BPKIHS, Dharan, Nepal \\ Received: September 20, 2019 \\ Accepted: September 30, 2019 \\ Published: January 31, 2019
}

Cite this paper:

Koirala S, Adhikari K, Khadka S. Spontaneous Rupture of an Ovarian Dermoid Cyst Associated with IntraAbdominal Chemical Peritonitis: Characteristic CT Findings. Nepalese Journal of Radiology 2019;9(14):52-54. http://dx.doi.org/10.3126/njr.v9i2.27433

\begin{abstract}
Spontaneous rupture of mature cystic teratoma is a rare complication which results in leakage of the liquefied sebaceous contents into the peritoneum leading to acute or chronic peritonitis. We report a case of a 23-year-old female who presented with pain abdomen, abdominal distension and fever. Contrast enhanced abdominal CT scan showed right adnexal complex cystic lesion with discontinuity in its wall along with features of peritonitis.
\end{abstract}

Keywords: Mature; Peritonitis; Rupture; Teratoma

\section{INTRODUCTION}

Dermoid is the most common ovarian neoplasm comprising between 10 to 25 percent of ovarian tumours. The tumor can rupture causing leakage of the sebaceous contents into the peritoneum and resulting in peritonitis. However, this is a rare complication, occurring in less than $1 \%$ of cases. ${ }^{1}$ We present the CT findings of a case of spontaneous rupture of mature cystic teratoma causing chemical peritonitis.

\section{CASE REPORT}

A 23 years female presented to the OPD with history of pain in right iliac fossa for one month with increased intensity in last five days. Patient also complained of abdominal

Correspondence to: Dr. Sapana Koirala

Senior Resident

Department of Radiodiagnosis and Imaging BPKIHS

Dharan, Nepal

Email: ksapana11@gmail.com distension and constipation for last 3 days. Patient had fever for one day. On physical examination abdomen was soft and nontender with mild distension. No mass was 
palpable on abdominal examination. On USG there was a cystic lesion of size $\sim 6 \times 5.5 \mathrm{~cm}$ in right adnexal region with internal echoes and septations within along with mild fluid collection with internal echoes in abdomen and pelvis. Her medical and family history were unremarkable. Contrast enhanced abdominal CT scan showed thick irregular walled cystic lesion with fat content and soft tissue component with focus of calcification within (s/o rokitansky nodule) in right adnexa. These features were consistent with dermoid cyst. There was a focal defect in superior aspect of the wall of cyst (likely the site of rupture). The CT also showed diffusely thickened peritoneal lining along with inflamed omentum and mesentery with moderate free fluid in abdomen and pelvis along with focal fat attenuating areas in bilateral sub-diaphragmatic region ( $\mathrm{s} / \mathrm{o}$ chemical peritonitis).

\section{Operation}

Patient underwent emergency exploratory laparotomy. There was a multilobulated cystic lesion of size measuring $15 \times 15 \mathrm{~cm}$ with ruptured wall and containing cheesy material along with hair within. The omentum and mesentery was grossly inflamed with adherent bowel loops with cheesy material present in all quadrants of abdomen and pelvis. Patient underwent right salpingo-oopherectomy followed by adhesiolysis of bowel loops followed by thorough peritoneal lavage.

\section{Pathology}

Histopathological findings were consistent with mature cystic teratoma.
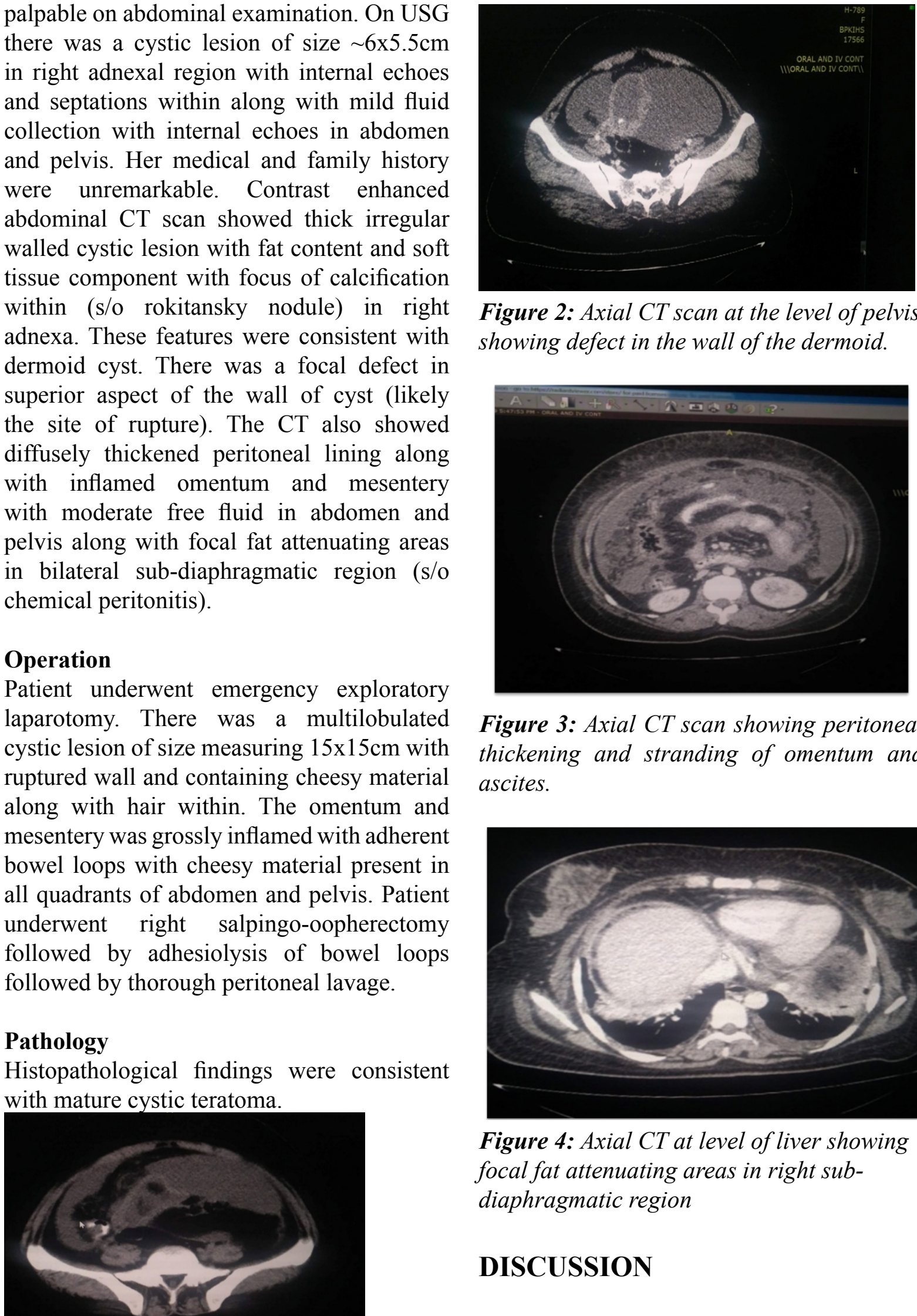

Figure 2: Axial CT scan at the level of pelvis showing defect in the wall of the dermoid.

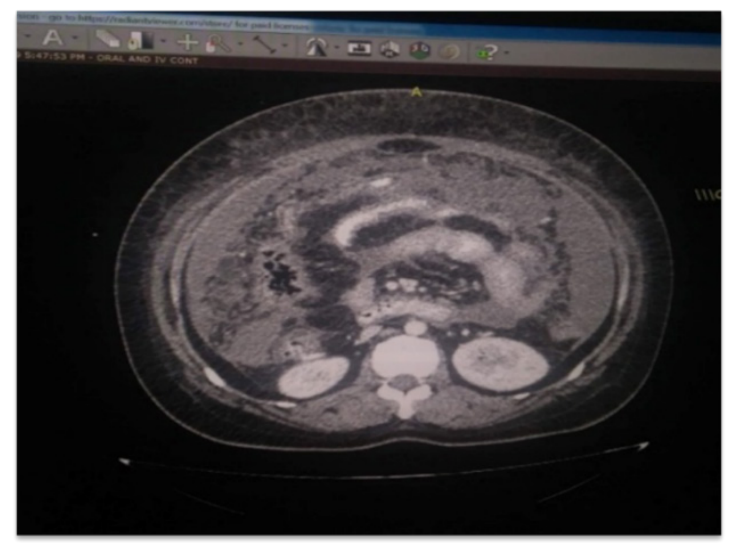

Figure 3: Axial CT scan showing peritoneal thickening and stranding of omentum and ascites.

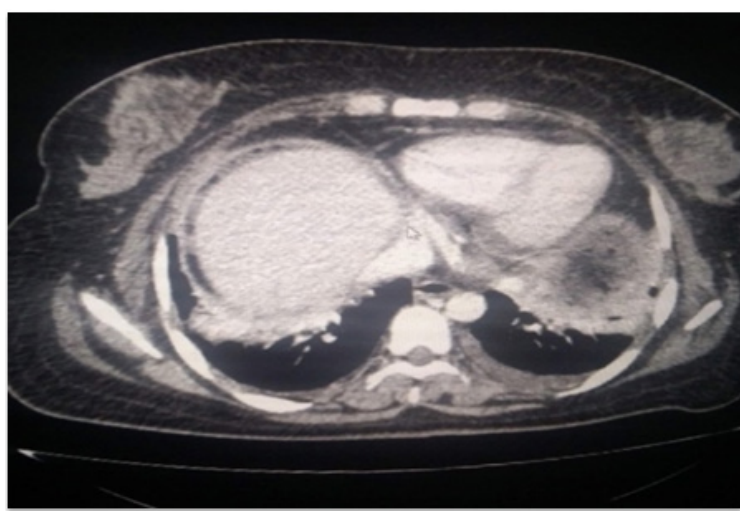

Figure 4: Axial CT at level of liver showing focal fat attenuating areas in right subdiaphragmatic region

\section{DISCUSSION}

Figure 1: Axial CT scan of pelvis shows right adnexal dermoid with focus of calcification.

Mature cystic teratomas are one of the most common benign ovarian neoplasms 
accounting for 10 to $20 \%$ of all ovarian tumours. $^{2}$ The peak incidence is reported between 20 and 40 years of age. ${ }^{3}$ The complications include torsion (16\% of ovarian teratomas), rupture (1\%-4\%), malignant transformation (1\%-2\%), infection (1\%), and autoimmune hemolytic anemia $(<1 \%){ }^{4}$ Rupture causes leakage of the liquefied sebaceous contents into the peritoneum, which irritates the peritoneum and leads to acute or chronic inflammation. ${ }^{5}$ At US, CT, and MR imaging, accurate diagnosis of a ruptured ovarian teratoma can be accomplished when the discontinuity of the wall is noted. The presence of ascites and a distorted or flattened shape of the tumor suggest tumor rupture, thereby indicating surgery. Acute or chronic peritonitis can manifest as ascites, diffuse or focal omental infiltration, and inflammatory masses involving the omentum and bowel. ${ }^{6}$ Whenever imaging findings of peritonitis are seen in case of mature cystic teratoma, the possibility of rupture should be kept in mind and the integrity of the tumor wall should be carefully evaluated.

\section{CONCLUSION}

Rupture of mature cystic teratoma is a rare complication and can cause life threatening chemical peritonitis. Timely diagnosis and intervention can be lifesaving.

\section{CONFLICT OF INTEREST}

None

\section{SOURCES OF FUNDING}

None

\section{REFERENCES}

1. Comerci JJ, Licciardi F, Bergh PA, Gregori C, Breen JL. Mature cystic teratoma: a clinicopathologic evaluation of 517 cases and review of the literature. Obstet Gynecol 1994;84(1):22-28. Available from: https://europepmc.org/article/ med/8008317 [Accessed 23rd June 2019].

2. MATZ MH. Benign cystic teratomas of the ovary. Obstet Gynecol Surv 1961;16(5):591-605. https://doi. org/10.1097/00006254-19611000000001

3. Lakkis WG, Martin MC, Gelfand MM. Benign cystic teratoma of the ovary: a 6-year review. Canadian journal of surgery. Journal canadien de chirurgie 1985;28(5):444-446.

4. Park SB, Kim JK, Kim KR, Cho KS. Imaging findings of complications and unusual manifestations of ovarian teratomas. Radiographics ;28(4):969$983 . \quad$ https://doi.org/10.1148/ rg. 284075069

5. Rha SE, Byun JY, Jung SE et al. AtypicalCT and MRI manifestations of mature ovarian cystic teratomas. AJR Am J Roentgenol 2004;183(3):743750. $\quad$ https://doi.org/10.2214/ ajr.183.3.1830743

6. Fibus TF. Intraperitoneal rupture of a benign cystic ovarian teratoma: findings at $\mathrm{CT}$ and MR imaging. Am J Roentgenol 2000;174(1):261262. https://doi.org/10.2214/ ajr.174.1.1740261 